\title{
Trends and Characteristics of AIDS Mortality in the Rio de Janeiro City After the Introduction of Highly Active Antiretroviral Therapy
}

Valéria Saraceni, Marly Marques da Cruz, Lilian de Mello Lauria and Betina Durovni
Rio de Janeiro City Health Department, Rio de Janeiro, RJ, Brazil

\begin{abstract}
We examined the characteristics of AIDS mortality in Rio de Janeiro city from 1995 to 2003. During this period, highly active antiretroviral therapy with protease inhibitors was made available, and it changed the pattern of the epidemics. There was a $47.5 \%$ reduction in the number of AIDS deaths within the period, with an increase in the proportion of women among the deceased; their schooling was lower than that of the men, similar to the trends of the national-level epidemics. The main place of death changed from university hospitals to emergency rooms. The proportion of cases reported to the National Diseases Surveillance System (SINAN) reported only through the death certificate remained high. Although there is free distribution of antiretrovirals by the public health system, many patients still lack access to diagnosis and treatment. We need to give priority to access to anti-HIV testing and treatment, to increase the quality of care and to look into the issue of adherence in order to further reduce AIDS mortality.

Key Words: AIDS, mortality, antiretrovirals.
\end{abstract}

Prior to the advent of combined antiretroviral therapy in 1996, using protease inhibitors, also called HAART (highly active antiretroviral therapy), the only means to avert the development of full-blown AIDS was prophylaxis of opportunistic infections [1].

Once one of the main causes of death in Brazil and in other parts of the world, AIDS-related mortality dropped dramatically in places where antiretrovirals (ARV) became widely available. Although many advances in the treatment of AIDS have been made, mortality is still a tremendous public health problem, and the analysis of its profile is of critical importance for planning disease-control strategies.

The number of deaths due to AIDS in Brazil fell 30.6\% between 1995 and 1999 [2]. However, this drop did not follow the same pattern in all regions of the country;

Received on 28 January 2005; revised 11 May 2005.

Address for correspondence: Dr.Valéria Saraceni. Rua Cupertino Durão, 219/B/404, Leblon, Zip code: 22441-030. Rio de Janeiro RJ, Brazil. Phone: 21 22498235. Fax: 21 22747542. E-mail: valeria@alternex.com.br

The Brazilian Journal of Infectious Diseases 2005;9(3):209-215 (C) 2005 by The Brazilian Journal of Infectious Diseases and Contexto Publishing. All rights reserved. there were considerable disparities among the regions. In the city of Rio de Janeiro, the decrease in the number of AIDS-related deaths started in 1996, probably reflecting the use of double ARV therapy and prophylaxis of opportunistic infections [3]. The pattern of decrease changed in 2000, assuming a stable trend from then on.

AIDS was the second cause of death among men 20 to 34 years old and in women 25 to 34 years old in São Paulo State in 1998 [4]. The mortality rate for the state was 13.1/100,000 inhabitants in that year.

In various studies, the large reduction in mortality has been attributed to the impact of HAART on HIVpositive patients [5,6]. AIDS mortality begins to fall when ARV becomes available. Palella et al. found a significant decrease in the relative risk of death among AIDS patients in a cohort study; this decrease was directly related to the gain of quality in ARV therapy, measured by the number of drugs in a prescribed regimen [7].

In order to determine the possible causes for the stabilization of AIDS-related mortality in the city of Rio de Janeiro after 1999, we linked and analyzed three secondary databases: SIM (Mortality Surveillance Database), SINAN (National Diseases Surveillance 
Database) and SICOM (AIDS Drugs Control System - Rio de Janeiro).

\section{Materials and Methods}

We used the databases SIM, SINAN and SICOM for the analysis of AIDS-related mortality between 1995 and 2003. The Epidemiological Surveillance and Vital Statistics Coordination of the Rio de Janeiro city Health Department provided the population estimate [8].

The SIM was implemented in 1975, after the unification of various models of death certificates into one called the Declaration of Death (DD), facilitating knowledge about mortality trends in Brazil. The DD is the document that contains the information that will be entered into the SIM database, and it must be generated for every case of death within the country [9].

The codification of all causes of death is based upon the International Classification of Diseases (ICD), which is periodically revised, so that it can cover all global realities and include newly described diseases. The acquired immunodeficiency syndrome was described while the ninth revision of the ICD was in effect. The code that indicated the disease and included AIDS among the immune disorders (Chapter 3) was 279.1, deficiency of cell-mediated immunity [10]. In the tenth revision, which was implemented in 1990, AIDS was moved to chapter 1 , among the infectious and parasitic diseases, under the codes B20 to B24. The ICD-10 was introduced in Brazil in 1996 [11].

The National Diseases Surveillance System (SINAN) was implemented in 1990 in order to standardize information on mandatory reported diseases, the data for which had begun to be collected in 1975. SINAN made it possible to study the distribution of these diseases all over the country, with data entered at the municipal or state health department levels.

The SINAN - AIDS database consists of individual reports of AIDS cases according to the National Case Definition for Adults [12]. Among the criteria, there is one called "death exceptional criterion"; it is used only when AIDS is diagnosed after the death of the individual. An AIDS case can be reported through this criterion if the DD of an individual 13 years of age or older includes: 1) AIDS mentioned in one field of the DD, and the case cannot be put under another AIDS definition criterion after epidemiological investigation; or 2) HIV infection mentioned, along with diseases related to HIV infection, and the epidemiological investigation resulted inconclusive.

Periodically, the Epidemiological Surveillance and Vital Statistics Coordination of the city of Rio de Janeiro Health Department sends all DD that have AIDS as basic cause of death to the STD/AIDS Program. This program initiates surveillance routines to determine if the individuals have already been reported as AIDS cases previous to death and are already included in the SINAN database. When a case is not found, a new report is made, using the death criteria indicated above.

The STD/AIDS Program/Transmissible Diseases Coordination of the Rio de Janeiro city Health Department maintains the databases for SINAN-AIDS and the Rio de Janeiro AIDS Drugs Control System (SICOM).

Subjects older than 12 years old and living in the city of Rio de Janeiro, having AIDS as the basic cause of death, were selected. The temporal distribution of death cases, the mortality rate per 100,000 persons/ year and the proportional distribution by sex, age, educational level and hospital category were studied from 1995 to 2003. The places of death (hospitals) were categorized by the institution's affiliation in order to monitor the temporal distribution of AIDS-related deaths at those locations.

The linking of the three databases was done with the software RECLINK [13], using the following variables: name, date of birth and the mother's name, when available. The resulting databases were scrutinized for duplicities of records and occurrence of the same individual in more than one record.

After linking SIM with SINAN-AIDS, we were able to determine the proportion of cases that were or were not reported to SINAN. We used SICOM to gather the information regarding use of $\mathrm{ARV}$ prior to death, since all patients receiving free ARV are registered at a public health unit. 
We used the chi-square test $\left(\chi^{2}\right)$, with a level of significance of $5 \%$, to check for homogeneity of proportions and to establish linear trends in the statistical analysis (EpiInfo 6.04, CDC/WHO, 1996). Simple linear regression was used to evaluate the temporal pattern of deaths (SPSS 9.0).

Ethical protocols for research involving human beings were followed. All the data were analyzed together, without including individual variables that could permit identification. The database remained within the city of Rio de Janeiro Health Department, which is the institution primarily responsible for its safety.

\section{Results}

We observed a drop in the absolute numbers of AIDS deaths between 1995 and 1999, with a slight increase in 2000. From 2000 to 2003, the number remained stable (Table 1). The descending shape of the mortality rate curve shifted from 1999 to 2000; again there was a slight downward shift in 2001, returning in 2003 to a level similar to 1999 . The mortality rate dropped from $26.8 / 100,000$ in 1995 to $13.2 / 100,000$ inhabitants in 1999. Between 2000 and 2003, it varied between 14.2 and 13.6/100,000 inhabitants.

After a $49.1 \%$ reduction in the number of deaths from 1995 to 1999 , the discrete upward shift in the curve in 2000 was an event not observed since 199495 (data not shown). From 1995 to 2003, the total observed reduction was $47.5 \%$, showing that the downward trend was not maintained after 1999.

There was a significant increase in the contribution of women over the years $(p<0.0001)$. Through the years, the proportion went from $79.2 \%$ in men and $20.8 \%$ in women in 1995 to $66.7 \%$ in men and $33.7 \%$ in women in 2003. The reduction in the number of deaths by sex maintained the same pattern throughout the years. The linear trend towards reduction was significant for both men $(\mathrm{p}=0.002)$ and women $(\mathrm{p}=$ 0.001 ) from 1995 to 1999 . However, from 2001 on, the upward trend in the number of deaths reported in
2000 was maintained among women; while in men there was a drop in 2001, and an upward shift in 2002. The linear trend from 1999 to 2003 was not significant for men $(p=0.839)$ or women $(p=0.683)$.

The highest proportion of deaths by age group (80.8\%) was concentrated among those from 20 to 49 years old (Table 2), maintaining the same pattern for both sexes. There was a significantly increased trend in the proportion of deaths among those aged 50 years and more from 1998 on $(\mathrm{p}=0.0031)$.

Regarding educational level (Table 2), death of subjects with less than eight years of schooling increased proportionally throughout the years $(\mathrm{p}=<0.0001)$. Also, infected women were less educated then men, suggesting a greater vulnerability to HIV infection.

Figure 1 shows the pattern of distribution of deaths by hospital affiliation; there was a decrease in the proportional involvement of teaching hospitals, with a consequent increase of public emergency hospitals, administrated by state and municipal governments, as the place of death $(\mathrm{p}<0.0001)$. Deaths that occurred in teaching hospitals decreased from $22.9 \%$ in 1995 to $13.2 \%$ in 2003 , while those in public emergency hospitals as a whole rose from $31.3 \%$ to $51.9 \%$ in the same years.

The proportion of cases reported from DD among all cases reported to SINAN had a significant linear increment ( $p<0.0001$ ) from 1995 to 2002 . The same analysis was made among the deceased in the SINAN database and this proportion was even higher. The year 2003 was not included in this analysis because of the delay of case reporting that constrained the number of cases in the database (Table 3 ).

There was a significant increase $(\mathrm{p}<0.0001)$ in the number of patients with prior use of ARV among the death cases, starting in 1997, the year that we initiated the nominal database for ARV distribution, which allowed linkage by names (Table 4). The proportion increased from 1997 to 1999 ( $p<0.0001$, $\chi 2$ for trend), followed by a reduction from 1999 to 2003 ( $\mathrm{p}=0.0023, \chi 2$ for trend). Unfortunately, more than $50 \%$ of the subjects had never used ARV therapy, despite free drug distribution by the public health sector in Brazil. 
Table 1. Distribution of AIDS deaths, by year of occurrence, AIDS mortality rate per 100,000 inhabitants, total and by sex - Rio de Janeiro, 1995-2003

\begin{tabular}{lcccccr}
\hline & \multicolumn{2}{c}{ Total } & \multicolumn{2}{c}{ Men } & \multicolumn{2}{c}{ Women } \\
\hline Year & Number & Rate & Number & Rate & Number & Rate \\
\hline 1995 & 1,507 & 26.75 & 1,203 & 45.06 & 304 & 10.50 \\
1996 & 1,295 & 23.51 & 1,015 & 38.92 & 280 & 9.85 \\
1997 & 1,018 & 18.02 & 759 & 28.41 & 259 & 8.82 \\
1998 & 847 & 14.58 & 614 & 22.57 & 233 & 7.51 \\
1999 & 743 & 13.22 & 525 & 19.67 & 218 & 7.52 \\
2000 & 786 & 14.17 & 543 & 20.83 & 243 & 8.28 \\
2001 & 717 & 12.89 & 464 & 17.82 & 253 & 8.54 \\
2002 & 779 & 13.85 & 536 & 20.32 & 240 & 8.13 \\
2003 & 778 & 13.62 & 516 & 19.22 & 262 & 8.68 \\
\hline
\end{tabular}

Source: SIM (Department Helath of Rio de Janeiro) and IBGE, 2003.

Table 2. Proportional distribution of AIDS deaths, by age group and educational level-Rio de Janeiro, 1995-2003

\begin{tabular}{cccccc}
\hline & & Age group & \multicolumn{3}{c}{ Educational level } \\
\hline Year & $<$ 20 years & 20-49 years & $\mathbf{2}$ 50 years & $<$ 8 years & $\geq$ 8 years \\
\hline 1995 & 2.5 & 81.7 & 15.8 & 55.9 & 44.1 \\
1996 & 2.9 & 82.8 & 14.3 & 61.0 & 39.0 \\
1997 & 2.9 & 83.8 & 13.3 & 62.8 & 37.2 \\
1998 & 3.7 & 82.4 & 13.9 & 66.2 & 33.8 \\
1999 & 3.7 & 799 & 16.5 & 55.7 & 44.3 \\
2000 & 2.9 & 79.5 & 17.6 & 61.3 & 38.7 \\
2001 & 3.8 & 79.1 & 17.0 & 67.8 & 32.2 \\
2002 & 3.9 & 79.0 & 17.1 & 64.7 & 35.3 \\
2003 & 2.7 & 75.6 & 21.7 & 63.9 & 36.1 \\
\hline
\end{tabular}

Source: SIM (Department Helath of Rio de Janeiro), 2003.

Figure 1. Proportional distribution of AIDS deaths, according to hospital affiliation in Rio de Janeiro, 1995-2003.

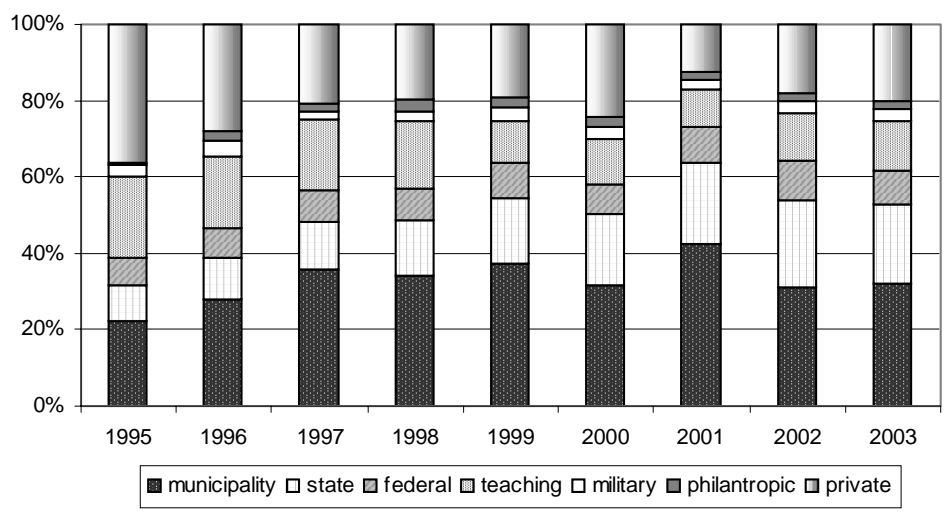

Source: SIM (Department Helath of Rio de Janeiro), 2003. 
Table 3. Proportional distribution of AIDS deaths, by reporting from the Declaration of Death (DD), among reported cases and known death cases reported in SINAN, Health department of Rio de Janeiro, 1995 - 2002

\begin{tabular}{lcrcr}
\hline & \multicolumn{2}{c}{ Reported cases } & \multicolumn{2}{c}{ Known deaths } \\
\hline Year & $\begin{array}{c}\text { Other } \\
\text { criteria }\end{array}$ & DD & $\begin{array}{c}\text { Other } \\
\text { criteria }\end{array}$ & DD \\
\hline 1995 & 98.4 & 1.6 & 96.7 & 3.3 \\
1996 & 91.5 & 8.5 & 79.9 & 20.1 \\
1997 & 83.8 & 16.2 & 61.4 & 38.6 \\
1998 & 81.6 & 18.4 & 50.3 & 49.7 \\
1999 & 78.3 & 21.7 & 41.1 & 58.9 \\
2000 & 75.6 & 24.4 & 33.5 & 66.5 \\
2001 & 72.7 & 27.3 & 29.0 & 71.0 \\
2002 & 70.9 & 29.1 & 25.2 & 74.8 \\
\hline
\end{tabular}

Table 4. Proportional distribution of AIDS deaths, according to previous use of HAART, available since 1997, Rio de Janeiro, 1997-2003

\begin{tabular}{ccc}
\hline Year & No HAART & HAART \\
\hline 1997 & 82.6 & 17.4 \\
1998 & 70.4 & 29.6 \\
1999 & 54.1 & 45.9 \\
2000 & 55.5 & 44.5 \\
2001 & 57.2 & 42.8 \\
2002 & 58.7 & 41.3 \\
2003 & 60.1 & 39.9 \\
\hline
\end{tabular}

Source: SIM and SICOM (Department Helath of Rio de Janeiro), 2003.

\section{Discussion}

There was a gradual drop in AIDS-related mortality in the city of Rio de Janeiro from 1995 to 1999 , with an atypical performance in 2000 , when a slight increase in the number of deaths occurred. This was followed by a decline in 2001, which continued until 2003, with a total reduction of $47.5 \%$. The mortality rate fell, following the same pattern as found for the country, in which there was a $27.1 \%$ decline in the mortality rate from 1995 to 2002 [14]. The mortality pattern that we found in Rio de Janeiro city was equivalent to that found at the country level, with an increasing participation of women, young adults and those with low educational level.

In Rio de Janeiro state, the AIDS mortality rate increased from 11.8/100,000 in 1991 to 18.7/100,000 inhabitants in 1995, prior to the introduction of HAART in clinical practice [15]. During 1995, Rio de Janeiro city, which accounted for $70 \%$ of the AIDS cases within the state, had an AIDS-related mortality rate of 26.75/ 100,000 ; in 2003, that rate had decreased to $13.62 /$ 100,000 . For the whole country the rate dropped from $9.7 / 100,000$ in 1995 to $6.3 / 100,000$ in 2002 [15].

In order to better evaluate the shift from specialized hospitals to public emergency hospitals in 1997-98, 
we have to take into consideration some reports of AIDS deaths described in some teaching hospitals. In $1988,58.3 \%$ of admitted AIDS cases had death as the outcome at the Hospital Universitário Clementino Fraga Filho (HUCFF- Rio de Janeiro Federal University). In 1994, the death ratio decreased to $24.7 \%$ [16]. At another teaching hospital, GaffreeGuinle of the University of Rio de Janeiro (UNIRIO), the mortality among patients admitted to the AIDS ward increased from $36.4 \%$ in 1990 to $51.2 \%$ in 1994 [17]. There was a significant association between death and no prior outpatient consultation $[\mathrm{OR}=3.29$ (CI 95\% 1.17-9.25)]. At the Infectious Diseases Institute Emilio Ribas in São Paulo, AIDS mortality decreased from $29 \%$ in 1995 to $19.8 \%$ in 1999 . The non-use of ARV prior to admittance was strongly associated with death [OR = 3.8] [18].

We also noticed that $33.7 \%$ of AIDS deaths occurred in private hospitals in 1995 , decreasing to $10.7 \%$ in 2001, with an upward shift to $20.3 \%$ in 2003.

Factors that may have contributed to the change in the pattern of the place of death of severe AIDS cases were the lack of emergency services at the teaching hospitals, where there are only referred admissions, a better clinical follow-up of the outpatients with greater clinical expertise and better equipment, and the fact that personnel in general emergency hospitals are not as well trained to deal with severely-affected AIDS patients. A qualitative survey concerning the care delivered to AIDS patients in some emergency rooms in the city of Rio de Janeiro showed poor quality of care because healthcare workers had little knowledge about HIV/AIDS [19]. A shift towards better quality in the emergency care of this type of patient is crucial to their survival and depends directly on the implementation of a continuous medical training process at those units.

The first relevant question regards the ability of emergency services to deliver adequate clinical care to AIDS patients, who often arrive at those services without knowing their HIV status but are already suffering from opportunistic infections. As a consequence, they probably will not survive the episode that motivated the hospital admission [20]. It has already been reported that patients who received their HIV infection diagnosis within the month that followed the AIDS clinical diagnosis had a worse chance of survival $(\mathrm{p}<0.001)$ [20].

Another relevant question is access to HIV testing and the possibility of an early diagnosis of the HIV infection. For asymptomatic individuals it is not enough to make the test available, they must perceive their own risk. Useful and easy to understand information about HIV infection and transmission routes must reach the communities, in order to stimulate the population to seek counseling and testing at the health services, which must have the tests available. Public health units need to have a laboratorial structure that can give a rapid response to the population and healthcare workers well prepared to deliver counseling on HIV testing.

The availability of HAART at public health clinics in Brazil has brought another challenge. Although drugs are given for free, this alone is not a sufficient condition to make people adhere to the treatment regimens. One of the consequences of non-adherence to therapy is the emergence of resistance to ARV, which makes therapy inefficacious. This phenomenon may explain some deaths among the ARV-users group [21]. An ARV therapy adherence evaluation was done in selected public clinics in Brazil, and the adherence prevalence was $75 \%$. The individual characteristics linked to non-adherence were to have less than two years of schooling, and treatment at a small clinic, with less than 100 patients [22]. The level of adherence considered ideal and enough to suppress the viral load is $95 \%$ [23].

\section{Conclusion}

The AIDS death cases, mainly those not encountered in the official information systems (SINAN and SICOM), were probably due to a huge number of patients that reached the emergency rooms with severe opportunistic infections, evolving to death without the benefit of prior HIV testing. Our study reinforces the need for better access to quality care, in both 
specialized clinics and emergency services and, in particular, greater attention to HAART adherence. It is also important to have better access to HIV diagnosis, allowing the earlier introduction of ARV therapy, before immunodeficiency has developed.

Our study corroborated others that have demonstrated an association of AIDS therapy and mortality reduction. This analysis can contribute to the planning of new strategies for AIDS care and to public health policies to increase the early HIV diagnosis. The reduction of the AIDS-related mortality remains a challenge to be faced, and it may be accomplished with some of the actions pointed out in this paper.

\section{References}

1. Colford J.M., Jr., Segal M., Tabnak F., et al. Temporal trends and factors associated with survival after Pneumocystis carinii pneumonia in California, 1983-1992. Am J Epidemiol 1997; 146:115-27.

2. Fonseca M.G.P., Barreira D. A Evolução da Mortalidade por AIDS no País, segundo sua Distribuição Geográfica. Brasília: Ministério da Saúde; 2000. Report No.: Year XIII No. 3.

3. Saraceni V., Cruz M.M., Tiago S.M.H., et al. Descriptive analysis of AIDS-related mortality after introduction of HAART in Rio de Janeiro City, Brazil. XIV International AIDS Conference, Barcelona, Spain, 2002.

4. Santo A.H., Pinheiro C.E., Jordani M.S. [Aids as underlying and associated causes of death, State of S. Paulo, Brazil, 1998]. Rev. Saude Publica 2000;34:581-8.

5. Wong T., Chiasson M.A., Reggy A., et al. Antiretroviral therapy and declining AIDS mortality in New York City. J Urban.Health 2000;77:492-500.

6. CDC (Centers For Disease Control And Prevention). HIV/ AIDS Surveillance Report. Atlanta, GA: US Department of Health and Human Services, CDC; 1997. Report No.: 9. $19 \mathrm{p}$.

7. Palella F.J., Jr., Delaney K.M., Moorman A.C., et al. Declining morbidity and mortality among patients with advanced human immunodeficiency virus infection. HIV Outpatient Study Investigators. N Engl J Med 1998;338:853-60.

8. Prefeitura da Cidade do Rio de Janeiro, Secretaria Municipal de Saúde: Números da Saúde: Indicadores por Área Programática 2004 Jun 2 Available from www.saude.rio.rj.gov.br.
9. FUNASA (Fundação Nacional de Saúde). Guia de vigilância epidemiológica. 5. 1998. Brasília, Ministério da Saúde.

10. Buchalla C.M., Laurenti R., Ribeiro A.F., et al. [Evaluation of the use of the International Classification of Diseases for the codification of AIDS]. Rev. Saude Publica 1996;30:479-82.

11. Mello-Jorge M.H.P., Gotlieb S.L.D., Laurenti R. A saúde no Brasil: análise do período 1996 a 1999. 2001. Brasília, Organização Pan-Americana de Saúde.

12. Secretaria de Vigilância em Saúde.Programa Nacional de DST e AIDS. Critérios de definição de casos de aids em adultos e crianças. [60], 1-56. 2003. Brasília, Ministério da Saúde. Série Manuais.

13. Camargo K.R., Jr., Coeli C.M. [Reclink: an application for database linkage implementing the probabilistic record linkage method]. Cad Saude Publica 2000;16:439-47.

14. Secretaria de Vigilância em Saúde.Programa Nacional de DST/AIDS. Boletim Epidemiológico de AIDS. Brasília: Ministério da Saúde; 2004. Report No.: Year XVII No. 1.

15. Lemos K.R., Valente J.G. [AIDS mortality in the State of Rio de Janeiro, 1991-1995]. Cad Saude Publica 2001; 17:957-68.

16. Rapparini C.S., Martins M.M.C., Peixoto C.A.M., Nogueira S.A. Comparação clínico-epidemiológica de pacientes com SIDA internados em serviço especializado em intervalo de 6 anos. Rev Soc Bras Med Trop 1995;28(Supp 1):217.

17. Thuler L.C., Hatherly A.L., Goes P.N., Almeida e Silva JR. [Mortality descriptors in HIV in patients]. Rev Saude Publica 1998;32:572-8.

18. Casseb J., Orrico G.S., Feijo R.D., et al. Lack of prior antiretroviral therapy is associated with increased mortality among hospitalized patients with AIDS in Sao Paulo, Brazil. AIDS Patient.Care STDS. 2001; 15:271-5.

19. Santos-Filho E.T., Menezes A.V.Q., Durovni B., et al. A qualitative study on care for PWAs in emergencies revealing demand for a new epidemiological surveillance strategy in Brazil. In 2000.

20. Castilla J., Sobrino P., De La F.L., et al. Late diagnosis of HIV infection in the era of highly active antiretroviral therapy: consequences for AIDS incidence. AIDS 2002;16:1945-51.

21. Recsky M.A., Brumme Z.L., Chan K.J., et al. Antiretroviral resistance among HIV-infected persons who have died in British Columbia, in the era of modern antiretroviral therapy. J Infect Dis 2004; 190:285-92.

22. Nemes M.I., Carvalho H.B., Souza M.F. Antiretroviral therapy adherence in Brazil. AIDS 2004; 18 Suppl 3:S15-S20.

23. Paterson D.L., Swindells S., Mohr J., et al. Adherence to protease inhibitor therapy and outcomes in patients with HIV infection. Ann Intern Med 2000;133:21-30. 